\title{
Trends in green transformation economic policy: experience of leading countries and russia
}

\author{
Inobbat Alieva ${ }^{1, *}$, Saltanat Omurova $^{2}$, Dmitry Kuznetsov ${ }^{3}$, Inga Pankina ${ }^{1}$, and Irina \\ Shchepkova ${ }^{1}$ \\ ${ }^{1}$ Immanuel Kant Baltic Federal University, Russia \\ ${ }^{2}$ The Jusup Balasagyn Kyrgyz National University, Kyrgyzstan \\ ${ }^{3}$ Kaliningrad State Technical University, Russia
}

\begin{abstract}
Given the demand for green economic growth and sustainable development, many economic practices demonstrate different rates and characteristics of the transition to a green economy, which in one way or another are determined by the initial socio-economic factors and the economic policy implemented by the state. Stimulating green growth and increasing the well-being of society through the rational use of natural resources, natural capital and ecosystems require the elaboration and development of alternative measures for ensuring the rational use of natural resources, the development of environmental innovations and human capital. An equally important factor contributing to green growth is the formation of a state policy of green economic growth, as well as tools and mechanisms for its implementation. The conceptual foundations of a supranational green growth policy have already been developed and the methodological basis has been elaborated. The study of the experience and best practices of green growth in different countries allows us to identify certain shortcomings that require a deeper study and revision of state regulation documents. In addition, the post-Covid economy requires a separate consideration from the point of view of both the relevance of the policy of green growth and the measures and tools for its implementation. Thus, the study of modern trends and principles of the implementation of the state policy of green growth is a topical area of research that requires critical rethinking for the introduction of more constructive measures for reaching the set goals and objectives.
\end{abstract}

\section{Introduction}

Green economic growth and the demand for corporate social responsibility are the trends that have shaped the modern macroeconomic policy of sustainable economic growth based on the environmental industry. The concept of green economic growth was adopted in the 1960s and quickly became widespread due to its rationality and care for future generations. From year to year, the transformation of society and economy towards green economic growth has

\footnotetext{
${ }^{*}$ Corresponding author: inobbat@mail.ru
} 
become more complex and large-scale. It affected almost all levels of economic activity. A new model of consumer behaviour based on the principles of environmental protection and environmentally oriented choice has formed. Such rapid development of the concept of green economy could have never been developed at such a pace without proper government regulation and control. It is the political will of national governments that guarantees a successful implementation of economic policy aimed at sustainable growth and green transformation of society. In this context, the study of the mechanisms of state regulation of the transition to clean production through a comparative analysis of the macroeconomic approaches of European countries-leaders in the green economy and best practices from Russia is relevant and timely.

The progressive transition to the green economy and green transformation of society have revealed several important factors facilitating green economic growth. First of all, it is a strong commitment of national governments, which has translated into the launch of numerous economic support programmes. Another important factor is the elaboration of macroeconomic policy aimed at sustainable development. The creation of supranational institutions and associations offering a general methodology of transition as well as a conceptual foundation for the global transformation of the world economy was another important factor facilitating green economic growth.

In September 2015, the UN held a summit on sustainable development and the main goals of the millennium. Participating countries adopted the resolution "Transforming our world: an agenda for sustainable development until 2030". The document was a "blueprint to achieve a better and more sustainable future for all by 2030". There are 17 main goals on the agenda. Their achievement will contribute to a balanced economic development by prioritizing the green industry, corporate social responsibility and a strong environmental policy implemented by states. In 2016, at the G-20 summit, heads of states recognized the need for the elaboration of a single financial conception of green economic growth and the development of common approaches to green and social investment mechanisms. All these factors and events have laid a solid foundation for the formation of a global institutional system for the green transformation of economy and society. No transformation is possible without a sound national policy. This public policy should be based on a generally accepted methodology and quantitative and qualitative assessment of economic growth.

Today, the institutional system for the green transformation of economy and society comprises interconnected elements that determine the conceptual foundations of this transformation, as well as principles, tools and mechanisms of the green growth strategy implementation. Yet, it is premature to talk about a smooth and progressive transition of the world economy to green principles. The pace of the green transformation is not as fast as countries would want it to be. Consequently, the reasons and constraints slowing down the green transformation of economy and social responsibility of society require further research.

\section{Materials and methods}

In this study, we employed empirical methods of research - description, interpretation and comparison of statistical data, as well as theoretical methods of formal and dialectical logic. Several stages of the study required performing economic-dogmatic analysis and interpretation of economic concepts. The material of research included economic reports, research publications on the conceptual assessment of the factors facilitating and hampering the green transformation of economy, sustainable growth and social responsibility of business.

The following key terms were used in the study: green economy, instruments of state economic policy, and green economic growth. These terms are defined in the global conception for sustainable transformation of economy and society. It is these concepts that 
form a special methodological basis for the elaboration of practical green solutions in the field of resource conservation, green policy implementation and the development of social partnership to achieve Millennium Goals.

The study is practice-oriented since it explores the global approach to the green transformation of economy and society as well as national projects aimed at achieving sustainable growth. The accumulated experience of the green transformation of economy can now be critically revised from the standpoint of a constructive approach and economic benefits aimed at and gained. The COVID-19 pandemic has changed the world economy. It has to adapt to the changing economic conditions and adjust to some deviations from the intended green principles. For instance, during the first year of the pandemic (2019-2020), the consumption of disposable plastic products increased significantly. This led to environmental damage and a potentially serious threat to nature. At the same time, it is the COVID-19 pandemic that has demonstrated the vulnerability of the brown economy. A postpandemic recovery economy must be built on new, more sustainable and equitable principles.

\section{Results and Discussion}

The formation of the theory of sustainable transformation and the green paradigm is associated with the ecological vein of economic research, which originated in the mid-70s of the twentieth century. The concept green economy was introduced by the British scientists Pearce, Markandii and Barbier in their work "Blueprint for a Green Economy" published in 1989. In 2018, Nordhaus received the Nobel Prize "for integrating climate change into longterm macroeconomic analysis". He is rightfully considered 'the father of climate change' for introducing the climate dimension into economic theory and practice. According to the author, an increase in the well-being of the world's population should be ensured through the introduction of rational consumption and production, and social and technological progress should be achieved only through measures of environmental protection [Nordhaus c. 341].

Since 2008, after the announcement of the UN Green Economy Initiative (GEI), there have been numerous interpretations of this concept, which was often referred to as "green growth" or "greening economy". The World Bank has proposed the following definition of green growth - "it is the growth that is efficient in terms of the use of natural resources; clean in terms of minimizing pollution and environmental impact; and sustainable from the point of view of natural disasters". The OECD combines economic growth and sustainable development in the definition of green growth, which is described as "simultaneously ensuring the quality and quantity of natural capital and preserving the ecosystem services on which the well-being of the entire nation is based". Green growth cannot be achieved without targeted investment, competition and innovation that will foster sustainability and open new economic perspectives.

Another important concept related to the green economy is that of low-carbon economy/development, which is related to energy efficiency and cleaner production, the main goal of which is to reduce greenhouse gas emissions.

The theory and practice of bioeconomy is an integral part of the green transformation since it is connected with energy efficiency, sustainable agriculture, food production, and the efficient use of waste and renewable energy. In other words, bioeconomy is an economy based on biotechnology that uses renewable biological raw materials to produce energy and materials.

To sum up, green economy today has a solid conceptual foundation and has gained rich practical experience, which makes it possible to speak about the formation of an integrated economic model, which is now being critically revised and perfected. A schematic representation of the system of green economic growth based on resource-saving technologies and corporate social responsibility can be illustrated as follows: 


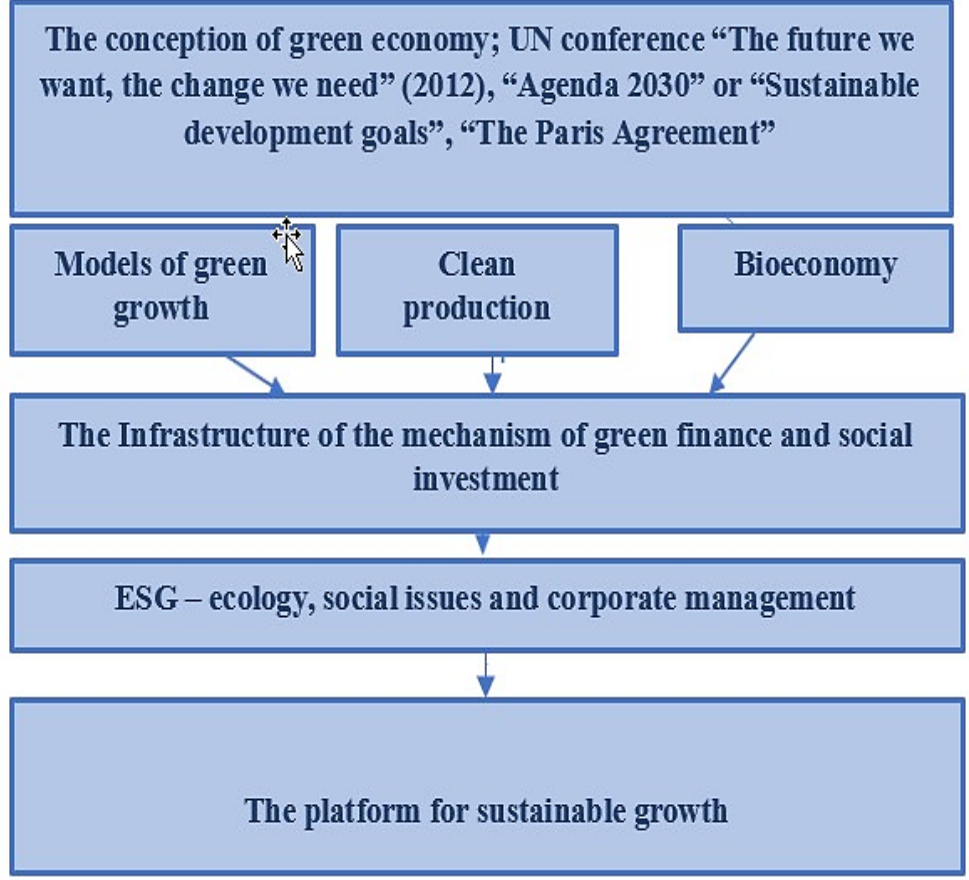

Fig. 1. Green Growth Economy.

The idea of green economy in one form or another has already been adopted by many developed countries. Measures to promote green growth are considered an effective means of combating global economic recession. The UN resolution adopted in 2015 and signed by heads of more than 162 states outlined 17 main goals of sustainable development to be achieved by 2030 . The document focuses on the following areas: affordable high-quality education, gender issues, fight against inequality; health and social equality; carbon reduction and sustainable industries; food, land, water and the oceans; cities and communities; and, last but not least, innovative growth. The economic policy of the participating countries has been developed and implemented in line with the UN document, which, in turn, involves the transformation of the principles of state regulation and its instruments.

However, our research has shown that the concept of green economy has both advantages and disadvantages. Many experts agree that the main advantage of the theory and practice of green growth can be attributed to the alleged increase in the well-being of people, which is achieved through new sources of income and subsequent growth of income, the creation of new jobs in the environmental industry and the provision of capital and resource conservation of production. To achieve positive effects, green economy requires investments of at least $2 \%$ of world GDP, which can be allocated by countries, provided they have a national policy of green economic growth.

It is also worth noting that a reduction in state subsidies for the overconsumption of natural capital will free about $1 \%$ of world GDP a year. In the long-term perspective, high economic returns are expected from the implementation of the green scenario of the development of the world economy. A change in the institutional foundations of business, the introduction of additional environmental standards, as well as a demand for increasing corporate social responsibility may incur additional costs and increase a tax burden. But in 
the long term, the introduction of the principles of green economy will allow companies to increase their competitiveness and achieve competitive business advantages.

The social effects of green transformation can already be seen in many European countries - leaders in this field. Heavy investment in clean transport, the construction of energy-efficient residential buildings, green transport infrastructure are the current trends in many leading European countries, including Denmark, Sweden, Germany, the Czech Republic, Finland and the countries of the Baltic region.

Apart from these positive trends, many experts also mention the high costs of green transformation, which can restrain or even sabotage the green transformation of the economy. Given the pandemic, the real costs of the green transformation are voiced more and more often. This can be explained by a decline in the world economic growth rates. Moreover, the regional differentiation of the world economy, quite pronounced even before the COVID-19 pandemic, was an insurmountable obstacle for countries having a low level of economic development. During the pandemic, it turned into a serious barrier to the green transformation. Insufficiently effective mechanisms of green growth and poor initial economic conditions often hinder green growth due to the lack of immediate economic benefits and positive social impact.

In the current conditions of the pandemic economy, it is rather difficult to talk about the implementation of an integral unified policy of green development. At the same time, a number of European countries have achieved good results in the implementation of a comprehensive state policy of green and sustainable growth as well as the implementation of large-scale green projects. There is an understanding that a green project is the one that tackles one of the three problems - climate change (reduction of carbon emissions), preservation of natural resources and biodiversity, and reduction of pollution.

Countries implementing a national green growth policy employ the following tools:

1) adoption and implementation of a policy of reducing greenhouse gas emissions;

2) protection of the environment and natural capital;

3) launching energy saving and energy efficiency programmes,

4) investments in renewable energy sources,

5) improving air quality.

Our research has shown that some European countries have a high green economy index.

The selected countries were analyzed according to the instruments of green economic growth. The results are presented below. Table 1 shows the ranking of countries in this study. A five-point scale was chosen, where 0 is the absence of an instrument and 5 is the maximum number of instruments used.

Table 1. Comparative analysis of green economy instruments used by European countries and Russia.

\begin{tabular}{|c|c|c|c|c|c|c|c|}
\hline Indicator & $\begin{array}{c}\text { Denma } \\
\text { rk }\end{array}$ & Sweden & Austria & Finland & $\begin{array}{c}\text { Switzela } \\
\text { nd }\end{array}$ & $\begin{array}{c}\text { Nor } \\
\text { way }\end{array}$ & $\begin{array}{c}\text { Russi } \\
\mathrm{a}\end{array}$ \\
\hline $\begin{array}{c}\text { Climate } \\
\text { change tax } \\
\text { policy }\end{array}$ & 5 & 4 & 3 & 3 & 3 & 4 & 1 \\
\hline $\begin{array}{c}\text { Control over } \\
\text { greenhouse } \\
\text { gas } \\
\text { emissions }\end{array}$ & 5 & 5 & 5 & 4 & 5 & 4 & 2 \\
\hline $\begin{array}{c}\text { Curring } \\
\text { fossil fuel } \\
\text { subsidies }\end{array}$ & 4 & 3 & 5 & 3 & 2 & 5 & 1 \\
\hline $\begin{array}{c}\text { Coal refusal } \\
\text { policy }\end{array}$ & 4 & 5 & 5 & 4 & 5 & 4 & 2 \\
\hline Tree policy & 5 & 4 & 5 & 4 & 5 & 5 & 4 \\
\hline
\end{tabular}


Table 1. Continued.

\begin{tabular}{|c|c|c|c|c|c|c|c|}
\hline $\begin{array}{c}\text { Protection } \\
\text { of the } \\
\text { environment } \\
\text { and natural } \\
\text { capital }\end{array}$ & 5 & 5 & 5 & 4 & 4 & 5 & 1 \\
\hline $\begin{array}{c}\text { Energy } \\
\text { saving } \\
\text { programmes }\end{array}$ & 5 & 5 & 5 & 4 & 5 & 5 & 2 \\
\hline $\begin{array}{c}\text { Renewable } \\
\text { energy } \\
\text { investments }\end{array}$ & 3 & 4 & 4 & 2 & 4 & 3 & 5 \\
\hline $\begin{array}{c}\text { Air quality } \\
\text { index }\end{array}$ & 5 & 5 & 5 & 5 & 5 & 5 & 5 \\
\hline
\end{tabular}

Figure 2 is a radar chart that shows the strengths and weaknesses of each country in the transition to a green economy. In our research, we paid special attention to Russia and its results in comparison with the European countries - leaders in the field.

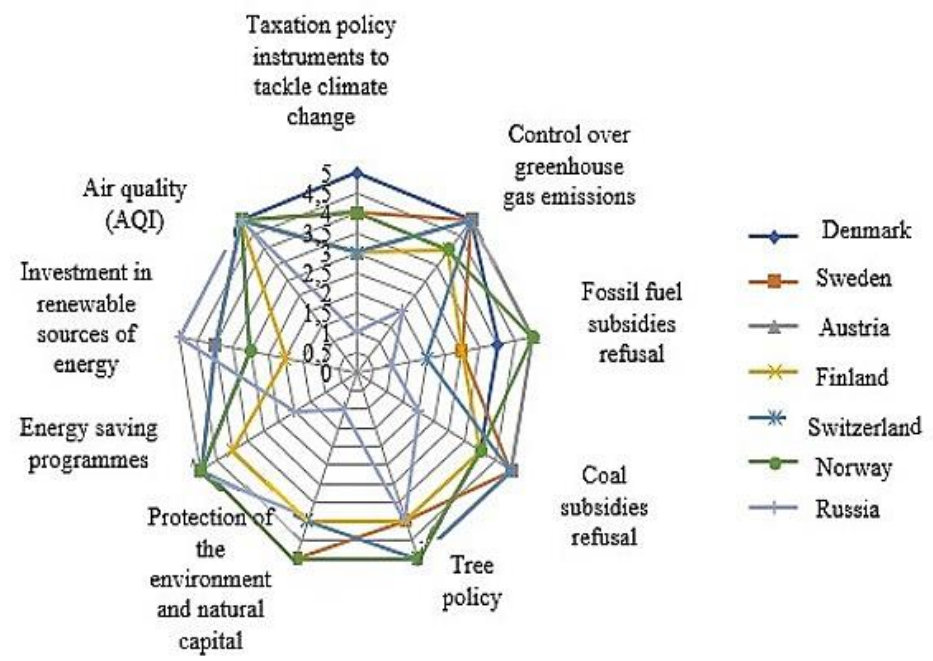

Fig. 2. Comparative assessment of the implementation of the policy of green economy in European countries and Russia.

As it is shown in Fig. 2, Russia has been particularly effective in the following areas: improving the quality of air, investment in renewable sources (caused by a number of factors that are not always a consequence of success) and tree policy. However, Russia considerably lags behind the European countries in terms of tax instruments used to tackle climate change, control over greenhouse gas emissions, refusal to cancel subsidies for fossil fuel and coal, and environmental protection and energy-saving programmes.

Unlike European countries, Russia does not use tax instruments for stimulating the green transition. Currently, the legislation of the Russian Federation does not provide a legal basis for the introduction of taxation instruments in the field of environmental protection. Moreover, there is no term 'environmental tax'. Instead, there is a fine for polluting the environment and an ecological fee. However, the difference between real taxation instruments and the current ones is fundamental: tax authorities exercise a much stricter control over taxpayers compared with the soft measures Russia has been applying so far. In addition, the introduction of environmental taxes will foster a more responsible attitude of taxpayers to the protection of the environment. It is worth noting that a draft amendment to 
the Tax Code of the Russian Federation has been discussed since 2018. The document envisages the introduction of environmental taxes. Unfortunately, the amendments have not been adopted yet.

Another weak point in the development of the green economy in Russia is the reduction of greenhouse gas emissions. It is no secret that the extraction of fossil fuels is one of the leading industries in the Russian Federation. It is a source of Russia's high greenhouse gas emissions, which account for 5\% of global emissions, or about 1,600 megatons every year. Although this problem is not ignored, Russia still has unsatisfactory results in comparison with European countries.

No concrete steps have been taken to improve the situation concerning fossil fuel subsidies and coal-free policies. Unlike European countries, which are gradual closing coalfired power plants, Russia continues to invest in their construction and modernization. In this context, it is necessary to take into account the specifics of the Russian economy and the difference in the structure of the fuel and energy resources. However, environmentalists are already raising the question of adopting a long-term strategy of phasing out coal after the COVID-19 pandemic is over.

Environmental protection is a matter of serious concern in the Russian Federation. The country still lags behind European countries in many spheres of environmental protection, particularly in reducing greenhouse gas emissions, waste and the area of pollution (264 million $\mathrm{m} 3$ of polluted wastewater is discharged by oil processing enterprises; 98.3 tons of waste for 1 million rubles of GDP; pollution from road transport accounts for $97.3 \%$ of the total volume of pollution). Such a high level of pollution results from the specifics of the country's economy on the one hand and insufficiently pace of the transition to the principles of green economy in Russia. Consequently, the adoption of an appropriate taxation system could significantly contribute to a decrease in the volume of pollution.

Russia has launched many energy-saving programmes. The main goal of these programmes is to reduce the energy intensity of GDP and increase energy efficiency in all sectors of the national economy. At the moment, the Russian Federation is in the process of transition towards a green growth model where the GDP growth is not accompanied by an increase in energy consumption. The reason for Russia's slow progress in the implementation of energy-saving programmes is the peculiarities of energy consumption in the country as well as climatic characteristics that are different from most European countries.

Based on the analysis of the experience of the countries presented above, the following recommendations have been developed for a faster implementation of the green growth policy in Russia. It is recommended to:

1. Stimulate the use of solar panels in private homes in the regions with the highest number of sunny days per year (through subsidies proportional to the level of income).

2. Elaborate a state programme aimed to achieve a $10 \%$ share of renewable energy sources in the total volume of electric energy generation. At the moment, the share of renewable energy sources is $1 \%$, and according to experts' forecasts, oil reserves in the country will run out over the next thirty years.

3. Redirect part of the investment from the oil sector to alternative sources of energy. Since most equipment for the generation of renewable energy sources (for example, windmills) is expensive, it is necessary to launch domestic production not to import the equipment from Europe and China.

4. Invest in the development of geothermal energy in the Far East, the Caucasus, the Stavropol and Krasnodar Krais since this type of energy is inexhaustible and has no adverse environmental effects.

5. Reduce subsidies for oil and gas production and increase subsidies for alternative energy.

6. Create a state programme to monitor the reduction of greenhouse gas emissions. 
7. Use part of the energy produced by waste incineration for heating residential buildings and enterprises.

8. Close landfills for waste disposal and introduce systems for the distribution of waste by categories (accordingly, invest in waste processing plants).

9. Optimize production processes at enterprises through a more rational use of fuel resources and clean raw materials, improve the quality of wastewater treatment facilities to minimize the negative impact on the environment (wastewater discharge into water bodies, air pollution, etc.).

10. Use smart water meters and modern plumbing equipment to reduce water consumption; introduce modern technologies of wastewater treatment.

11. Increase awareness and participation of the population in the development of plans and policies of environmental protection; inform the media about new green technologies, their advantages and applications; demonstrate the need for personal contribution to environmental protection; increase the knowledge of each person (company) of their ecological footprint and form a more responsible attitude to environmental protection.

12. Build an effective system of environmental taxation in Russia to protect the environment and the health of the population; introduce environmentally friendly technologies and increase the tax burden for 'dirty' industries.

13. Introduce a tax for enterprises organizing unauthorized landfills of industrial hazardous waste, which requires special treatment.

Given climate change, Russia should elaborate a more systemic approach to environmental protection since the country has sufficient technological potential for this. Even without an increase in the use of natural resources, Russia can significantly improve the well-being of the population.

\section{Conclusions}

The analysis of economic policies of green transformation elaborated by countries made it possible to identify general trends and approaches that correspond to supranational environmental policies implemented globally. A common conceptual framework and methodology for the implementation of the economic policy of green growth should contribute to the development of the national system of sustainable development and the formation of a comprehensive state policy to support the green transformation of the economy and society. Each country should perform a thorough analysis of its starting conditions, natural resources and the availability of effective regulatory policy mechanisms. It is also important to take into account the specifics of green policy implementation given the Millennium Goals and the objectives set by the Paris Agreement.

A serious climate stress test, the COVID-19 pandemic, has affected the implementation of the medium-term policy of states on green transformation. According to experts, the postCovid economy is characterized by a continuing reduction in $\mathrm{CO} 2$ emissions, on average by $2.6 \%$ per year. This is a positive development. Yet, the concentration of $\mathrm{CO} 2$ in the atmosphere is increasing. It clearly demonstrates the inertia and time lag between the economic activity and geophysical processes, as well as the socio-economic consequences of these events. Therefore, a new international climate policy is required, which is based on brand new sophisticated technologies, charges for emissions as well as international cooperation.

The most important aspect of the modern economic policy of green transformation is the implementation of low-carbon technology projects that have a cumulative effect in terms of climate benefits and the development of infrastructure.

The cost of emissions can constrain the development of low-carbon innovation. International data show that the cost of $\mathrm{CO} 2$ emissions varies greatly: in Sweden, it was about 
$\$ 50$ per ton of CO2 (2019), in Argentina - \$ 1.2 per ton, and in Mexico - \$ 0.5 per ton. In 2019 , the global average cost of a ton of CO2 emissions was only $\$ 1.7$. More than $80 \%$ of countries do not charge for emissions at all.

It is noteworthy that the global policy in the field of sustainable development does not offer tools for assessing the responsibility of participating countries. According to Nordhaus, the 'free-rider' problem is particularly acute, when a country is a party to an environmental agreement, but does not fulfill its obligations under the agreement. This requires the introduction of certain liability in the form of fines or privileges.

A possible solution could be a climate club or a climate treaty, which will change the existing approaches to climate agreements. New climate agreements should be built on the principles of general and financial responsibility. Price for emissions and a system of financial penalties for polluters should be introduced.

\section{References}

1. S. N. Bobylev, Green economy. New paradigm of the country's development, 68 (2018)

2. D. W. Pearce, A. Markandya, E. R. Barbier, Blueprint for a Green Economy (1989)

3. D. V. Gnetova, S. M. Mironova, Pros and cons of introducing an environmental tax 38 (2019)

4. M. V. Tereshina, Theory and practice of social development, 5, 246 (2012)

5. P. Krugman, The New York Times (2010)

6. UNE, Green Economy Report: A Preview (2010)

7. K. Makiela, T. Misztur, Engineering Economics, 23(2), 137 (2012)

8. UNECE, From Transition to Transformation: Sustainable and Inclusive Development in Europe and Central Asia, 12 (2012)

9. J. of Cleaner Production, 18, 519 (2010)

10. K. Makiela, T. Misztur, Engineering Economics, 23(2), 137 (2012)

11. R. Schmalensee, Energy Economics, 34, 2 (2012)

12. The World Bank. Inclusive Green Growth: The Pathway to Sustainable Development (2012)

13. A. S. Bezverkhy, E. A. Kirov, Economics and Management, 119 (2018)

14. Yu.V. Evdokimova, Bulletin of the Catherine Institute, 48 (2019)

15. L. V. Pchelintseva, S. I. Tikhomirnov, Building Thermal Physics and Energy Saving, 447 (2010)

16. Fundamentals of state policy in the field of environmental development of the Russian Federation for the period up to 2030 (approved by the President of the Russian Federation on April 30, 2012), http // www.consultant.ru/

17. Decree of the President of the Russian Federation of 19.04.2017 No. 176 "On the strategy of environmental safety of the Russian Federation for the period up to 2025", http // www.consultant.ru/ 